\title{
A biblioteca pública entre a heterotopia e a utopia
}

\author{
The public library between a heterotopia and na utopian
}

\author{
Daniele Achilles \\ Doutora em Memória Social pela Universidade Federal do Estado do Rio de Janeiro - UNIRIO. \\ Professora do Departamento de Biblioteconomia da Universidade Federal do Estado do Rio de Janeiro - \\ UNIRIO. \\ E-mail: daniele.achilles@unirio.br \\ Hugo da Costa Bernardo \\ Graduando em Biblioteconomia na Universidade Federal do Estado do Rio de Janeiro - UNIRIO. \\ E-mail: dacosta.hugo@icloud.com
}

\begin{abstract}
Resumo
O presente trabalho tem como objeto a biblioteca pública, compreendida como instituição social, cultural e de memória. A partir da leitura de que, enquanto continua a distância entre a literatura do campo e da realidade sobre a qual ela se sustenta, este aparato institucional se mantém em crise, propomos uma releitura de suas bases conceituais. A investigação se classifica como teórica porque articula aspectos constitutivos da definição biblioteca pública, tais como sua missão, valor e funções, com suas potencias e poderes, colocando em questionamento conceitos correntes, a valorização comum e a utilidade efetiva dessa instituição. Para realizar tal recorrido, se optou por investigar o conceito "heterotopia" apresentado por Foucault (2013) em sua conferência homônima, para atualizar a noção de biblioteca como um espaço heterotópico, "espaço outro", e defender a noção de biblioteca pública a partir dessa perspectiva. O uso desse aparato conceitual nos fornece ferramentas necessárias tanto para analisar a experiência da biblioteca pública, como para evidenciar a diferença entre a perspectiva utópica (e de "corpos utópicos") e a perspectiva heterotópica tomada sobre essa instituição, como também para contribuir para a atualização da literatura acadêmica em Biblioteconomia Pública.
\end{abstract}

Palavras-chave: Biblioteconomia Pública. Biblioteca Pública. Heterotopia. Utopia.

\begin{abstract}
The present work has as an object the public library, understood as social, cultural and memory institution. Stemming from the reading that, as long as the distance between the field literature and the reality on which it underpins persists, this institutional and cultural equipment remains in crisis, we propose a rereading of its conceptual bases. The research is classified as theoretical because it articulates constitutive elements of the definition of public library, such as its mission, value and functions, with its powers and forces, calling into question current concepts, the common valuation and the effective usefulness of this institution. To conduct such course, it has been chosen to scrutinize the concept of "heterotopia" submitted by Foucault (2013) in his homonymous conference, in order to update the notion of public library as heterotopian space, "other-place", and to advocate the notion of public library from this perspective. The use of this conceptual apparatus provides us with the necessary tools both for analyzing the public library experience and for highlighting the difference between the utopian bias (and of "utopian bodies") and the heterotopian bias taken about this institution, likewise to contribute to the scientific literature in Public Librarianship.
\end{abstract}

Keywords: Public Librarianship. Public Library. Heterotopia. Utopia. 


\section{Introdução}

[...] no Brasil, [onde] o senso comum ainda reduz as funções sociais da biblioteca pública a um mero espaço de armazenamento de livros, acesso à leitura e de apoio à pesquisa escolar, [...] discutir e entender esta instituição como espaço público e os profissionais que nela atuam como agentes políticos colabora para reposicionar este tipo de equipamento cultural no cenário nacional (MACHADO; ELIAS JÚNIOR, ACHILLES, 2014, p. 116-117).

Na verdade, os diversos segmentos têm expectativas diferentes em relação ao papel da biblioteca pública. A indústria editorial acredita que o objetivo fundamental é a formação de um público leitor. Os educadores acreditam que a biblioteca deve ser alicerce do processo de ensino-aprendizagem. Os intelectuais acreditam que deve ser um espaço rico em literatura de ficção. O trabalhador comum não vê a biblioteca como um local para solucionar os problemas cotidianos (SUAIDEN, 2000, p. 57).

Há diversas maneiras de definir o que seria uma biblioteca pública (BP); cada uma das definições pode conter em si uma referência a algo vivido, a uma experiência, a uma narração verbal ou imagética sobre esse lugar (ideia de passado), pode ser um diagnóstico da situação atual deste equipamento cultural (ideia de presente), como também uma espécie de imagem especular do que essa instituição deveria ou pode vir a ser (ideia de futuro). Tais definições podem advir dos mais diversos segmentos que têm acesso ou não a esse tipo de biblioteca, podem abrir ou obstruir a possibilidade e a vontade de entrar em seu espaço, e também podem tanto corresponder à realidade quanto passar, citação a citação, pela legitimação de um saber científico ou comum. A Biblioteconomia Pública é representada assim como um campo de disputas narrativas, científicas e políticas no qual se executa o definir e, ao mesmo tempo, um campo que se (re)constitui a partir de seu produto discursivo final. Isso, também, de acordo com o requisito para a disseminação dessas definições: a existência de um meio que dê voz àqueles que vivenciam as bibliotecas públicas (BPs), aos responsáveis pelo desenvolvimento dos saberes da Biblioteconomia Pública, e aos atores políticos que participam na gestão desses espaços e que representam uma "classe bibliotecária" de profissionais da informação. As possibilidades de disseminação desses discursos vão determinar o grau de permutação do definir. Tal contexto produz, em suma, todo um imaginário de definições legitimadas profissionalmente, epistemologicamente, e de senso comum que contém em si ideias de passado, presente e futuro das bibliotecas públicas.

A proposta deste trabalho é, num primeiro momento, analisar algumas dessas ideias que tiveram historicamente como finalidade definir a BP, propondo a "heterotopologia" (ver na seção "Espaços outros e heterotopologia") como um ponto de vista possível para esta análise. O ponto de partida é um problema atual - uma crise - precisamente nos campos de saber e 
poder imanentes a essa determinada instituição, e que acaba por afetar sua efetividade comum. Para realizar essa análise, o texto foi dividido em duas partes: a) apresentação do conceito de heterotopia e utopia em Foucault, destacando os pontos principais à leitura biblioteconômica e atualizando-o a partir da literatura de nosso campo; b) aplicação dos conceitos anteriores ao conceito de biblioteca pública de forma a evidenciar a crise mencionada. A contribuição foucaultiana se dá a partir da menção a "bibliotecas" na emissão radiofônica de 1966 e no texto de 1967 (FOUCAULT, 2013a, 2013b), nas quais ele qualifica o termo amplo da instituição como "heterotopia do tempo que se acumula indefinidamente", "própria da cultura ocidental do século XIX”. Após uma atualização desse conceito, que a princípio é insuficiente em termos temporais, tipológicos e práticos, propomos uma maneira de utilizá-lo em confronto e aproximação com o conceito de utopia, explorado por Foucault em termos espaciais, mas que pode efetuar justamente a "conjunção da filosofia e do conceito com o meio presente" (DELEUZE; GUATTARI, 1992, p. 130-131, grifo dos autores). Por fim, esse conjunto conceitual será apresentado como um modo de rearranjar as relações de poder que constituem as BPs e o saber científico sobre elas, capaz de dar visibilidade a outros modos de funcionamento dessa instituição. Assim, o trabalho fará tensionar o tempo histórico, o espaço presente e a imagem de futuro das BPs; localizando-as entre a heterotopia e a utopia, enquanto "espaço outro" da crise.

\section{Heterotopia, Utopia e Biblioteca}

O conceito de heterotopia é foucaultiano. São, no entanto, poucas as aparições dele ao longo da obra do autor: é mencionado pela primeira vez no prefácio do livro As Palavras e as Coisas, de 1966, reapresentado em dezembro do mesmo ano com um sentido distinto e mais profundo, na emissão radiofônica Les héterotopies [“As heterotopias” (FOUCAULT, 2013a)] e revisado durante sua estadia na Tunísia, no ano seguinte, para uma conferência proferida no Cercle d'Études Architecturales, com o título Des espaces autres ["De espaços outros" (FOUCAULT, 2013b)]. Aparentemente, tendo em vista apenas essa pequena história do conceito dentro da obra de seu fundador, é um conceito ignorado por Foucault. Mas ele representa uma classificação dos espaços que receberam mais destaque por esse autor: o hospital psiquiátrico e a prisão. Edward Soja, entusiasta americano promotor da "heterotopologia", citado por Daniel Defert (2013, p. 34) pergunta, por nós: “Como [esse conceito] pode permanecer inexplorado durante vinte anos? Como não se compreendeu a 
importância nova do espaço e da espacialidade?” Defert (2013) coloca sua própria questão: “[...] poderíamos interpretar a distância entre essas duas datas, 1967-1984, e a história desse silêncio como a história de uma não recepção?” E ainda podemos nos perguntar, trazendo para nossa discussão: a distância entre 1967 e 2018, e a apropriação biblioteconômica pouco significativa do conceito devem ser interpretadas como a inadequação deste conceito a nossa área do conhecimento? A fim de responder de forma precisa (e negativa) a essa pergunta, falaremos em detalhes do conceito.

Primeiro, vamos destacar o sentido duplo que possui a noção de heterotopia em Foucault, após separá-la em dois momentos distintos: na primeira aparição, constituindo um sentido linguístico, e nas duas últimas, consolidando um conceito amplo referente ao espaço. Em seguida, vamos explorar a construção desse conceito a partir de suas imagens e princípios. Por fim, analisamos o lugar da biblioteca nessa definição, atualizando-o à luz da Biblioteconomia para na seção seguinte aplicar o conceito de heterotopia à biblioteca pública.

\section{Heterotopias de Foucault}

Sua primeira aparição está no seguinte trecho de As palavras e as coisas (FOUCAULT, 1999, p. xiii, grifo do autor), no qual ele fala de "um mal-estar evidente e difícil de vencer" que teve ao ler um texto de Jorge Luis Borges:

\footnotetext{
As utopias consolam: é que, se elas não têm lugar real, desabrocham, contudo, num espaço maravilhoso e liso; abrem cidades com vastas avenidas, jardins bem plantados, regiões fáceis, ainda que o acesso a elas seja quimérico. As heterotopias inquietam, sem dúvida porque solapam secretamente a linguagem, porque impedem de nomear isto e aquilo, porque fracionam os nomes comuns ou os emaranham, porque arruínam de antemão a "sintaxe", e não somente aquela que constrói as frases - aquela, menos manifesta, que autoriza "manter juntos " (ao lado e em frente umas das outras) as palavras e as coisas. Eis por que as utopias permitem as fábulas e os discursos: situamse na linha reta da linguagem, na dimensão fundamental da fábula; as heterotopias (encontradas tão freqüentemente em Borges) dissecam o propósito, estancam as palavras nelas próprias, contestam, desde a raiz, toda possibilidade de gramática; desfazem os mitos e imprimem esterilidade ao lirismo das frases.
}

Está neste trecho algo que se manterá nas outras definições do termo, ou seja, que ao contrário da (compreensão mais próxima da etimologia de) "utopia" — e "é preciso reservar esse nome para o que verdadeiramente não tem lugar algum" (FOUCAULT, 2013a, p. 21) — a heterotopia "desfaz os mitos”, “contesta”. Mas a definição presente nesse trecho é ainda vaga, e meramente linguística, localizável não no "real", mas na literatura, "em Borges". Segundo Defert (1997, p. 37), é pertinente a uma análise dos discursos, não dos espaços. 
A segunda e a terceira aparições na emissão radiofônica (FOUCAULT, 2013a) e na conferência (2013b), respectivamente, serão responsáveis pela abertura progressiva, ou melhor, pela "virada espacial" (spatial turn) do conceito de heterotopia ${ }^{1}$. É nesses textos que a heterotopia vai se relacionar com a utopia enquanto espaço, ou melhor, enquanto um “contraespaço", uma "utopia localizada", "situada", "lugar real fora de todos os lugares". A emissão e a conferência preservam semelhanças e diferenças ao discutir o conceito e suas vizinhanças conceituais; são duplas, e assim respondem pelo que "as heterotopias inquietam", e também, de acordo com Defert, à "curiosidade" gerada pelo prefácio de As palavras e as coisas. Nos dois textos, Foucault constrói um quadro imagético de exemplos de heterotopia e define seis princípios para uma "heterotopologia", conjunto que vai nos ajudar a entender o que foi definido como "heterotopia", o que diz a definição de "biblioteca como heterotopia" e, mais precisamente, o que pode ser a biblioteca pública como "espaço outro".

\section{"Espaços outros" e Heterotopologia}

Segundo Foucault (2013b, p. 116), as hetero-topias seriam literalmente "espaços outros", mas elas "assumem formas muito variadas, e talvez não se encontre uma única forma de heterotopia que seja absolutamente universal". Os exemplos de heterotopia que ele cita são: o colégio em sua forma do século XIX, o serviço militar, o "alhures" ou "nenhures" longe da família onde as primeiras manifestações da sexualidade viril deveriam acontecer (heterotopias de crise); as casas de repouso, as clínicas psiquiátricas, as prisões, os asilos para aposentados (heterotopias de desvio); o cemitério; o teatro, a sala de cinema, o jardim (e os tapetes), os jardins zoológicos; o museu e a biblioteca (heterotopias do tempo que se acumula indefinidamente); as feiras, "alocações vazias nos limites das cidades, que se povoam, uma ou duas vezes por ano, de barracas, estandes, de objetos heteróclitos, de lutadores, de mulheresserpente, de videntes", as estâncias de férias como as aldeias polinésias, as cabanas de Djerba (heterotopias não eternitárias, mas crônicas); a caserna; as termas dos muçulmanos, as saunas

\footnotetext{
${ }^{1}$ Esse caminho de espacialização não deve ser entendido como um progresso em direção a uma "verdade" do conceito, mas representa o desenvolvimento temporal dele ao longo da obra de Foucault. Alguns usos ainda escolheriam a abordagem primeira (de análise do discurso), como o de Knight (2014), e outros acabariam por flertar com ela, ao tentar descrever a topologia da biblioteca através da "ideia de passado", pela análise de narrativas ficcionais sobre a biblioteca (RADFORD; RADFORD; LINGEL, 2015).

2 "Quanto às heterotopias propriamente ditas, como se poderia descrevê-las, qual sentido elas têm? Poder-se ia supor não digo uma ciência, pois é um termo demasiadamente desgastado, atualmente, mas uma espécie de descrição sistemática que teria por objeto, em uma sociedade determinada, o estudo, a análise, a descrição, a 'leitura' - como se gosta de dizer hoje — desses espaços diferentes, esses outros lugares [...]: tal descrição poderia ser chamada de heterotopologia" (FOUCAULT, 2013b, p. 116).
} 
A biblioteca pública entre a heterotopia e a utopia

escandinavas (heterotopias de purificação); “famosos quartos que existiam nas grandes fazendas do Brasil e, em geral, da América do Sul" onde qualquer viajante poderia ser hóspede de passagem sem ter qualquer contato com o seio da família, "famosos quartos dos motéis americanos" onde a sexualidade ilegal "está absolutamente garantida e escondida, mantida a distância, sem ser, entretanto, consentida”, os bordéis (heterotopias de ilusão); as colônias, "sociedades puritanas que os ingleses fundaram na América", "extraordinárias colônias de jesuítas na América do Sul” (heterotopias de compensação); e o barco ${ }^{3}$ (FOUCAULT, 2013b, p. 116-121). Temos, a princípio, essas imagens.

Já o conceito há de ser criado pelas relações de vizinhança ou consistência interna (no caso, os princípios da heterotopologia) e por relações de vizinhança externa, ou exoconsistência (com o conceito de utopia, bem como a definição de cada instituição, por exemplo, a biblioteca), de acordo com Deleuze e Guattari (1992, p. 119). Abaixo, com base nos dois textos de Foucault (2013a; 2013b), interpretamos e resumimos os seis princípios criados como fundamento para a leitura dos "espaços outros", para uma heterotopologia:

i. cada cultura, sociedade ou grupo humano constitui sua(s) heterotopia(s) ${ }^{4}$;

ii. ao longo da história, uma sociedade pode organizar e transformar o modo de funcionamento das heterotopias, ou até fazê-las desaparecer ${ }^{5}$;

iii. a heterotopia tem como regra ou poder justapor em um único lugar real vários espaços que podem ser considerados incompatíveis;

$i v$. as heterotopias estão frequentemente associadas a recortes de tempo; abrem-se para o que se poderia chamar de heterocronia ${ }^{6}$, com a qual "se organizam e arranjam de um modo relativamente complexo";

$v$. as heterotopias possuem ou pressupõem sempre um sistema de abertura $e$ fechamento que simultaneamente as isola em relação ao espaço circundante e as torna penetráveis ${ }^{7}$;

$v i$. as heterotopias têm, em relação ao espaço restante, uma função contestatória que se desenvolve entre dois pólos: a criação de um espaço real e de um espaço ilusório ${ }^{8}$.

\footnotetext{
3 “O navio, essa é a heterotopia por excelência. Nas civilizações sem barcos os sonhos definham, a espionagem substitui a aventura, e a polícia, os corsários.” (FOUCAULT, 2013b, p. 121). Essa nota final mereceria a reflexão em separado, por se propor a ser o "espaço outro" real e mítico-metafórico "por excelência". Poderíamos propor um desvio dessa provocadora imagem do pensamento para outra: ao invés da ausência de barcos, a de bibliotecas. 4 "Poder-se ia talvez classificar as sociedades, por exemplo, segundo as heterotopias que elas preferem, segundo as heterotopias que as constituem" (FOUCAULT, 2013a, p. 21).

5 "Com efeito, cada heterotopia tem um funcionamento preciso e determinado no interior da sociedade, e a mesma heterotopia pode, segundo a sincronia da cultura em que se encontra, ter um funcionamento ou outro." (FOUCAULT, 2013b, p. 117).

6 "A heterotopia se põe a funcionar plenamente quando os homens se encontram numa espécie de ruptura absoluta com o seu tempo tradicional. Vê-se, assim, que o cemitério é mesmo um lugar altamente heterotópico, pois ele tem início com essa estranha heterocronia que é, para um indivíduo, a perda da vida, e essa quase eternidade em que ele não cessa de se dissolver e de desaparecer" (FOUCAULT, 2013b, p. 118).

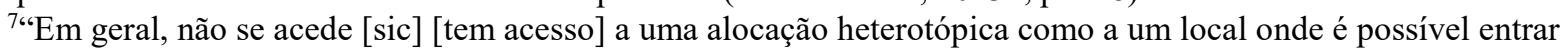
ou sair sem restrições. Ou bem se é para lá coagido — como no caso da caserna, da prisão —, ou bem é preciso submeter-se a ritos e purificações" (FOUCAULT, 2013b, p. 119).

8 “Ou bem elas têm o papel de criar um espaço de ilusão, que denuncia como mais ilusório ainda todo o espaço real, todas as alocações no interior das quais a vida humana é compartimentada (talvez seja esse o papel que, por muito tempo, tiveram os famosos bordéis, dos quais estamos agora privados). Ou então, ao contrário, o papel das heterotopias é criar um outro espaço, um outro espaço real, tão perfeito, tão meticuloso, tão bem arranjado quanto
}

Bibl. Esc. em R., Ribeirão Preto, v. 6, n. 2, p. 11-27, 2018. 
Daniele Achilles e Hugo da Costa Bernardo

A seguir, vamos apresentar a menção a "bibliotecas", no texto de Foucault, de forma a permitir um começo para a leitura heterotopológica das BPs (pesquisa em andamento).

\title{
Biblioteca como Heterotopia
}

Segundo Foucault, as bibliotecas (e os museus) são heterotopias próprias da cultura ocidental do século XIX, uma "ideia totalmente moderna" (FOUCAULT, 2013a, p. 25), algo pertencente "a nossa modernidade" (FOUCAULT, 2013b, p. 119). Seu modo de funcionamento haveria mudado em comparação com os séculos XVII e XVIII, quando deixou de ser "a expressão de uma escolha individual" para representar espacialmente

\begin{abstract}
a ideia de tudo acumular, a ideia de constituir uma espécie de arquivo geral, a vontade de encerrar em um lugar todos os tempos, todas as épocas, todas as formas, todos os gostos; a ideia de constituir um lugar de todos os tempos, que seja ele mesmo fora do tempo, e inacessível a sua corrosão; o projeto de organizar, assim, uma espécie de acumulação perpétua e indefinida do tempo em um lugar que não se moveria (FOUCAULT, 2013b, p. 119).
\end{abstract}

A partir desses desdobramentos, dos dois primeiros princípios e munidos do conceito de heterotopia (ver "Espaços outros e heterotopologia"), fornecer um olhar crítico inicial sobre essa construção de formas universais ("biblioteca", "museu”). A existência dessa categoria histórica, a "heterotopia", e a demanda pelo recorte contextual observado nesses dois primeiros princípios se vincula à necessidade de contestação do tipo universal e especificação das tipologias de biblioteca, o que é próprio a nossa área do conhecimento.

As ideias de "tudo acumular" e de organizar essa acumulação "do tempo" estiveram presentes tanto na biblioteca de Alexandria ${ }^{9}$ quanto no Mundaneum ${ }^{10}$ de Paul Otlet e Henri La Fontaine; elas se atualizam, de acordo com determinadas limitações territoriais e tecnológicas, no depósito legal realizado por bibliotecas nacionais, na construção de repositórios institucionais em bibliotecas especializadas e universitárias ou na perspectiva de consolidar bibliotecas públicas e comunitárias como espaços de memória. É evidente que esses exemplos não são desprovidos de contexto nem de idealidade, a depender da sociedade, do tempo histórico e as capacidades de produção e disseminação da informação em certos territórios. Mas

\footnotetext{
o nosso é desordenado, mal disposto e bagunçado. Isso seria a heterotopia não de ilusão, mas de compensação, e eu me pergunto se não é um pouco dessa maneira que algumas colônias funcionaram" (FOUCAULT, $2013 \mathrm{~b}, \mathrm{p}$. 120).

${ }^{9}$ Alexandria "é uma biblioteca de Estado, mas sem público, cuja finalidade não é a difusão filantrópica e educativa do saber na sociedade, e sim a acumulação de todos os escritos da Terra" (JACOB, 2008, p. 45).

${ }^{10}$ Mundaneum representa o sonho de um "repositório do saber mundial" (FERREIRA JR, 2006, p. 12).
} 
essas instituições não podem ser vistas, também, apenas como "resultado de determinados processos sócio-históricos", com o risco de recair em uma visão negativa das bibliotecas próxima dessa ideia de acúmulo e da ideia de passado daqueles que veem as BPs apenas como "lugar de armazenamento" (MACHADO; ELIAS JÚNIOR; ACHILLES, 2014, p. 116). A inserção do paradigma do acesso e de novas possibilidades para a atuação positiva de toda a diversidade de tipologias biblioteconômicas acrescenta o movimento deste debate, mas a sugestão que fornecemos nesta subseção já é suficiente para adotarmos o recorte das BPs.

\section{Biblioteca Pública como "Espaço Outro"}

Nos parágrafos seguintes, demonstraremos um panorama histórico das funções atribuídas às BPs, propondo a aproximação com o conceito de heterotopia a partir dos questionamentos fornecidos pelos primeiros dois princípios da heterotopologia (sempre em referência a sua descrição em "Espaços outros e heterotipologia") e pela elucidação feita na subseção anterior, construindo, assim, a ideia de crise e um referencial outro para a Biblioteconomia Pública. Utilizaremos como exemplo o caso das BPs brasileiras.

Por muito tempo as definições de BP estiveram centradas em um modo de funcionamento de biblioteca que se pode julgar erudito, já que servia mais a classe dos mais nobres do que à população em geral. Perspectivas mais recentes mostram a persistência essa característica - "O trabalhador comum não vê a biblioteca como um local para solucionar os problemas cotidianos" (SUAIDEN, 2000, p. 57). Tal fato pode ser observado tanto na Roma antiga, quanto na Europa do final do medievo, quando a invenção de Gutenberg possibilitou um acesso mais amplo às obras impressas (ou melhor, promoveu o aumento do número de itens informacionais e de sua disseminação), mas ainda o privilégio de alfabetização e leitura estava restrito a determinadas camadas sociais, como indica Martins (1996) e Battles (2003). Na modernidade, como enfatiza Escolar (1990) e Lemos (2008), a BP se tornou aberta para um público leitor e era financiada por mecenas e membros da classe dominante. Já em "nossa contemporaneidade", a partir da Revolução Industrial, os modos de produção se ampliaram, e segundo Jacob (2008), a importância das bibliotecas passou a incidir sobre sua visibilidade na construção de práticas sociais vividas por cada grupo social.

No caso do Brasil, o que se pode perceber é que essas instituições vêm sofrendo uma crise de identidade que remonta ao século XIX, época em que surgia nossa primeira BP em 
Salvador, na Bahia (SUAIDEN, 1989). Tal "crise identitária", que devemos atribuir à mobilização daquelas relações de poder e saber imanentes às BPs (ver Introdução), e portanto às mutabilidades dessa instituição enquanto heterotopia, interfere tanto em sua dimensão científica, quanto em sua dimensão prática, revelando problemas para toda a práxis biblioteconômica, incluindo-se aí a produção e definições que remetem a passado, ao presente e ao futuro, mas que não se encontram em uma efetividade direcionada ao comum.

Em busca de entender os sentidos atribuídos às BPs, sua missão e funções, além do impacto social que produzem e que sentido ganharam na atualidade, é necessário compreendêla a partir de sua história (e, fora deste artigo e no futuro, pelos métodos arqueológico e genealógico) explorando o como se concebeu e transformou a BP brasileira.

Cabe dizer que as BPs não nasceram de uma demanda social, mas sim, de uma iniciativa individual e particular. Tal fato, já esclarece uma intencionalidade primeira — o acesso à informação estaria voltado apenas para uma pequena parte da população, já que a maioria dela era analfabeta no início do século XIX, e permitindo que "homens letrados" almejassem levar cultura ao povo, reproduzindo o modelo colonial. Com as transformações ocorridas na segunda metade do século XIX, representadas pelo crescimento das cidades, expansão do setor bancário, utilização de novas tecnologias como o telégrafo e ferrovia, a sociedade rural foi se tornando urbano-industrial e novas oportunidades começaram a surgir. O Brasil alcançou então um total de vinte e sete BPs estaduais e municipais. A motivo de comparação, segundo dados do Sistema Nacional de Bibliotecas Públicas (SNBP) do Brasil, hoje o total é de seis mil e cinquenta e sete BPs municipais, distritais, estaduais e federais, nos vinte e seis estados e no Distrito Federal (dados de 2015). Veremos que nenhum desses números é suficiente para determinar, por exemplo, se as BPs brasileiras, tendo sido criadas no século XIX, assumiram desde então o lugar superior de "heterotopias de seu tempo", e a tarefa heterotopológica não tem a ver com isso, mas com a relação que essas instituições mantêm com um dado modelo político (como o já dito modelo colonial) ao fornecer acesso a certo tipo de informação a um grupo seleto de usuários ao longo do tempo. Essa relação também revela a dimensão utópica das bibliotecas: se podemos falar em uma "utopia do conhecimento" que tenderia a se tornar realidade, nos aproximando do que nos diz Ricœur (2015, p. 324) sobre a "utopia liberal humanitária" de Mannheim: 
A biblioteca pública entre a heterotopia e a utopia

Esta se funda principalmente na confiança no poder do pensamento, concebido como processo de educação e informação. [...] Em certo sentido, podemos dizer que a Universidade procede dessa utopia, pois a transformação da realidade advém por meio de um conhecimento melhor, uma educação mais elevada, etc. Tal forma é utópica enquanto denega, por vezes até ingenuamente, as verdadeiras fontes de poder que são a propriedade, o dinheiro, a violência, todas as forças que não são as da inteligência. Valoriza excessivamente a capacidade que a inteligência tem de formar.

Não vamos nos ater ao pensamento de Ricœur neste momento, pensador cuja concepção de poder difere da que defende Foucault.

No início do século XX, a instituição que é tema de nosso trabalho deteve, no Brasil, um "virtual” monopólio das informações impressas e praticava uma espécie de disseminação seletiva baseada na seleção dos usuários, já que o acesso era apenas voltado aos letrados. Por isso sua função foi desenvolvida inicialmente como educativa e cultural. Por muito tempo, a função das bibliotecas no Brasil era estritamente servir ao grupo dos colonos letrados. Mais tarde, as bibliotecas passaram a seguir outro caminho, isto é, das atividades voltadas às funções religiosas. No entanto, entre os anos 20 e 30, o regime republicano e o desequilíbrio da base econômica provocaram outro tipo de demanda. Isso ocorreu no mesmo momento em que o desenvolvimento industrial crescia e a sociedade carecia de profissionais que pudessem atuar nas indústrias e ocupar os novos cargos que começaram a surgir. Nesse momento, para que uma BP pudesse cumprir suas funções foi necessário se respaldar em alguma estrutura que legitimava sua missão, funções, deveres e fazeres.

Diante desta perspectiva, as BPs brasileiras começaram a se pautar nos manifestos da IFLA/Unesco (1949), que enxergam essas instituições a partir do viés de desenvolvimento de suas funções em face da realidade local da comunidade com a finalidade de identificar novas demandas (FUNDAÇÃO, 2010).

A partir daí a BP (enquanto imagem e ideia de futuro) passou a assumir outras funções, de acordo com a literatura publicada no Brasil. Verri e Neves (1977, p. 375) asseguram que "a biblioteca pública é a força viva a serviço do ensino, da cultura e da informação e como instrumento indispensável para fomentar a paz e a compreensão internacional". Antonio Miranda (1978, p. 1-2) assevera que a BP é "um fenômeno histórico em regime de mútua e permanente influência (interação) com o meio ambiente [...] a biblioteca é [...] uma célula viva". O autor ainda expõe algumas missões conferidas a essas instituições, são elas: "promover o idioma nacional; fornecer publicações oficiais; livros e outros materiais a estudantes; apoiar campanhas de alfabetização e fornecer livros aos não-alfabetizados; ser depositária do acervo 
da inteligência e da história; fornecer serviços de informação técnica e comercial" (MIRANDA, 1978, p. 2-5).

Nogueira (1983) compreende a BP como uma necessidade de toda e qualquer sociedade e que a criação delas como imposição pode levar a sociedade a considerá-la como um corpo estranho. Já Rabello (1987) vai ao encontro dessas ideias e estabelece que a função da BP em nossa sociedade é propor um constante questionamento que circula no meio bibliotecário que se incide a respeitos das bibliotecas populares, isto é, que cada vez mais elas substituiriam as públicas. Flusser (1980, p. 132) afirmava que "a biblioteca verdadeiramente pública é a transformação estrutural da biblioteca tal como existente hoje, em uma que participe do processo de dar a palavra ao não-público”. Ademais, o autor confere a essas instituições a função criativa, de suscitar a palavra, produzindo um discurso que valoriza a dimensão da criatividade e da mediação a partir de ações culturais.

Gomes (1981) ressalta a ideia de biblioteca como agência social organizada para servir às necessidades sociais, bem como manter a sociedade no que diz respeito às demandas por informação. Araújo (1985) faz ponderações genéricas sobre as funções das BPs e que essas instituições devem colaborar para reduzir as diferenças socioculturais porque assumem um importante papel na sociedade moderna. Campello e Andrade (1988, p. 176) indicavam que a BP "se apresentava como uma instituição tradicional [...] [e serviam] de apoio didático [ao ensino tradicional]. Milanesi (1986) apontou o desafio da BP tradicional em lidar com a marginalização de uma imensa parte da população brasileira que estava representada na figura dos analfabetos.

Emir Suaiden (1995, p. 19) pondera que "o objetivo da BP é melhorar a qualidade de vida da comunidade; a BP [era] a base fundamental do sistema educacional e cultural". O autor ainda esclarece que o objetivo mais primordial era a formação do hábito de leitura e que os acervos dessas bibliotecas deveriam estar em consonância com às necessidades da população. Almeida Júnior (1997) ao alertar para a falta de usuários nas bibliotecas teceu uma série de aspectos que justificaram tal situação: o estereótipo do bibliotecário; o hábito de leitura, que ressurge como uma concretização dos objetivos dessas bibliotecas; o livro intrinsecamente bom; o livro como verdade; como norma padrão; a democratização da informação; o apego ao silêncio, dentre outros (ALMEIDA JÚNIOR, 1997, p. 24-39).

Em 1994, a IFLA/Unesco ao lançar a última versão do Manifesto sobre Bibliotecas Públicas que vigora até hoje, descreve que uma BP “deve apoiar a tradição oral [...] assegurar 
o acesso dos cidadãos a todos os tipos de informação da comunidade local”. Almeida Júnior (2003) em busca de corroborar com as indicações desenvolvidas em textos sobre políticas públicas e outros mais acadêmicos pondera que às BPs podem ser vistas a partir de dois adjetivos: tradicional e alternativo, e defende que por essa via é possível traçar uma série de elementos que as configuram. Cunha (2003, p. 70) esclarece que a BP pode ser também reflexo de sua responsabilidade com a cidadania. Cunha e Santos (2005, p. 5) afirmam que às BPs devem modificar seu papel e admitir uma função mediadora da informação”. Brettas (2010) sustenta a dupla ideia de que a BP pode legitimar seu papel e influir nas dinâmicas políticas, contribuindo para a criação de "possibilidades de mudança, por uma nova ordem social, mais justa e inclusiva para todos" (Brettas, 2010, p. 118). Crippa (2015, p. [2-7]) pondera que a biblioteca deve ser encontro, permite a tecelagem de habilidades dos diletantes da vida que tentam instituir seus discursos sem deixá-los a outros protagonistas; é lugar de igualdade; é necessário a inovação para recuperar o sentido das dimensões dos serviços que oferecem; a biblioteca deve criar oportunidades como apresenta a IFLA/Unesco (1994); a biblioteca deve ser um empreendimento social e cultural da comunidade.

Ademais, Medeiros (2010, p. 13) aponta que as BPs (enquanto ideia de presente), em muitos países, "representam instituições vigorosas, consideradas basilares na organização social [...] fornecem o acesso ao conhecimento sem restrição a qualquer pessoa, sem qualquer distinção".

Retomando Deleuze e Guattari (1992) todo conceito é criado em virtude de problemas que emergem de um cenário histórico, social, político, econômico e cultural. O processo de compreender os problemas e tentar resolvê-los gera conceitos que se pode caracterizar como sólidos, isto é, aqueles que se colocam distantes das dinâmicas diárias, dos fazeres cotidianos e práticos que contribuem para a formação e desenvolvimento do tecido social. As perspectivas mais tradicionais apontam que as BPs podem ser definidas como instituições sociais, culturais e de memória e que têm suas funções determinadas em virtude de configurações sociais, políticas, econômicas, culturais e informacionais. Tal conformação acaba criando a generalização do conceito BP, excluindo-se assim, outras possibilidades de e vieses pelos quais tal conceito pode ser analisado. A maioria dos textos publicados e veiculados no Brasil apontam que as BPs "evoluem" de acordo com as transformações sociais. Refletir sobre "evolução" e relacioná-la à mudança significaria assumir uma posição e uma visão progressista vinculada à alteração das condições, como também da melhoria contínua dos aspectos e elementos que as 
constitui. Tal olhar pode, de certa forma, camuflar problemas, retrocessos, entraves e mazelas vivenciados por essas instituições.

Apenas com esse breve panorama de definições do que a biblioteca deve ser, podemos observar a ideia utópica de que essas proposições serão progressivamente realizadas, embora não sejam efetivamente localizáveis nessas instituições como um todo. As BPs são, ainda assim, lugares “outros", na medida em que são espaços que existem (mesmo sem atingir às proposições utópicas mencionadas) criados por uma necessidade informacional "pública", mesmo que as definições do que é o "público" e suas funções mudem ao longo do tempo — e mantenham essa instituição em crise e transformação. São essas algumas características que viabilizam o enquadramento dessa tipologia de biblioteca como heterotopia para além da "ideia de tudo acumular”, questão que está sendo desenvolvida em nossa pesquisa.

\section{Considerações finais}

Embora o espaço deste artigo tenha nos servido apenas ao início da exposição sobre o caráter de heterotopia e utopia das BPs, devemos nos voltar para a pergunta feita na segunda seção: a distância entre 1967 e 2018, e a apropriação biblioteconômica pouco significativa do conceito devem ser interpretadas como a inadequação deste conceito a nossa área do conhecimento? Definitivamente não. Ao longo do texto mencionamos algumas perspectivas possíveis sobre o tema, e na quase inexistente literatura ${ }^{11}$ que relaciona Biblioteconomia e heterotopia encontramos casos que fogem ao caráter político que consideramos inseparável do ponto de vista espacial, de saber e de poder como imanentes a esta instituição (ver a terceira nota de rodapé). Acreditamos que esta análise pode elucidar este caráter, de tal maneira que o caráter utópico e o heterotópico da literatura científica, dos manifestos e dos meios de

\footnotetext{
${ }^{11}$ Com base na bibliografia temática produzida por Peter Johnson (2018), apenas 2 dos 11 textos da seção 10 ("Museum and Library studies") têm as bibliotecas como objeto, e conseguimos recuperar apenas um, o de Radford, Radford e Lingel (2015), enquanto o outro tratava em particular do caso da Biblioteca Pública de Vancouver. Segundo o autor da bibliografia, a lista vai para além de 300 entradas, sob diversos temas. Já em uma pesquisa com recorte nacional nas bases BRAPCI e SciELO, dos três resultados totais, apenas um é da área de Biblioteconomia: o artigo de Moura (2014) aproxima o conceito de heterotopia em Foucault do contexto das bibliotecas públicas. A produção bibliográfica brasileira recente também chegou perto de nosso tema: o livro de Brayner (2018, p. 42), embora contribua para a aproximação dos conceitos foucaultianos com a Biblioteconomia brasileira ao "analisar o poder sofrido e, principalmente, exercido pela biblioteca a partir da identificação de certos mecanismos ali presentes, como a separação, a interdição e a vontade de verdade, ressaltando as possibilidades de resistência", não menciona o conceito foucaultiano de heterotopia que, em nossa pesquisa, é de especial importância para mobilizar de um jeito outro toda "caixa de ferramentas" conceitual do filósofo francês com o campo biblioteconômico. A obra se trata de um compilado genérico sobre o autor e não aprofunda a compreensão dos conceitos foucaultianos de modo que possa ser apropriado por pesquisadores, principalmente no campo da Biblioteconomia.
} 
A biblioteca pública entre a heterotopia e a utopia

informação sobre essas instituições seja mais explicitamente analisado dentro e fora dos ambientes acadêmicos. Dentro, a partir da análise conceitual, institucional, histórica, arqueológica, e genealógica. Fora, a partir da afirmação da centralidade que tem a escuta das vozes imanentes a essas instituições, que precisa de um meio para manifestar entre si suas ideias de presente, passado e futuro e concretizar o debate de saber e poder das BPs. É esta a tarefa de nossa pesquisa. Com Foucault, contribuir com um aporte teórico para “[...] criticar o funcionamento das instituições, que dão a impressão de serem neutras e independentes; criticálas $[\ldots]$ de tal maneira que a violência política, que sempre foi exercida de maneira obscura, [...] seja desmascarada, para que se possa combatê-la" (CHOMSKY, FOUCAULT, 2014, p. 51).

\section{Referências}

ACHILLES, D. Bibliotecas públicas brasileiras: sob a perspectiva da memória e experiência. 2018. 282 f. Tese (Doutorado em Memória Social) — Programa de PósGraduação em Memória Social, UNIRIO, Rio de Janeiro, 2018.

ALMEIDA JÚNIOR, O. F. Bibliotecas públicas e bibliotecas alternativas. Londrina: Eduel, 1997.

ALMEIDA JÚNIOR, O. F. Biblioteca pública: avaliação de serviços. Londrina: Eduel, 2003.

ARAÚJO, W. T. A biblioteca pública e o compromisso social do bibliotecário. Revista da Escola de Biblioteconomia da UFMG, Belo Horizonte, v. 14, n. 1, p. 106-122, 1985.

Disponível em:

<http://www.brapci.inf.br/index.php/article/view/0000002582/b803ce8f2b9d30e24e1a0f5f1a1 dbc51>. Acesso em: 24 out. 2018.

BATTLES, M. A conturbada história das bibliotecas. São Paulo: Planeta, 2003.

BRAYNER, C. A Biblioteca de Foucault: reflexões sobre ética, poder e informação. São Paulo: É Realizações, 2018.

BRETTAS, A. A biblioteca pública: papel determinado e determinante na sociedade. Revista do Instituto de Ciências Humanas e da Informação, Rio Grande, v. 24, n. 2, p. 101-108, 2010. Disponível em: 〈https://periodicos.furg.br/biblos/article/view/1153〉. Acesso em: 24 out. 2018.

CAMPELLO, B. S.; ANDRADE, M. E. A. Fontes de informação para bibliotecas públicas e comunitárias brasileiras: uma proposta para seu estudo nos cursos de biblioteconomia.

Revista da Escola de Biblioteconomia da UFMG, Belo Horizonte, v. 17, n. 2, p. 173-185, 1988. Disponível em:

<http://www.brapci.inf.br/index.php/article/view/0000002034/8090ec0b10ab89cb69da45536 4afe846/>. Acesso em: 24 out. 2018. 
CHOMSKY, N.; FOUCAULT, M. Natureza humana: justiça vs. poder: o debate entre Chomsky e Foucault. São Paulo: WMF Martins Fontes, 2014.

CUNHA, V. A. A biblioteca pública no cenário da sociedade da informação. Biblos, v. 4, n. 15, abr./jun. 2003. Disponível em: 〈http://eprints.rclis.org/5540/>. Acesso em: 10 jul. 2018.

CUNHA, V. A.; SANTOS, L. A. N. Sociedade do conhecimento, políticas públicas de informação e às bibliotecas públicas municipais de Salvador. In: CINFORM, 5., 2005. Anais... Salvador: UFBA, 2005.

CRIPPA, G. Pensando o espaço público do presente: a biblioteca pública em sua função social. DataGramaZero, Rio de Janeiro, v. 16, n. 2, abr. 2015. Disponível em: <http://www.brapci.inf.br/index.php/article/download/52938>. Acesso em: 25 out. 2018.

DEFERT, D. Heterotopia: tribulações de um conceito entre Veneza, Berlim e Los Angeles. In: FOUCAULT, M. O corpo utópico, as heterotopias. São Paulo: N-1, 2013a. p. 33-55.

DELEUZE, G.; GUATTARI, F. Geofilosofia. In: DELEUZE, G.; GUATTARI, F. O que é a filosofia? Rio de Janeiro: Editora 34, 1992.

ESCOLAR, H. S. História das bibliotecas. 3. ed. Salamanca: Madrid: Fundación Germán Sánchez Ruipérez: Pirámide, 1990. (Biblioteca del Libro, C).

FERREIRA JR., H. S. Otlet, realizador ou visionário? O que existe em um nome? Ciência da Informação, Brasília, v. 35, n. 2, p. 9-16, maio/ago. 2006. Disponível em:

<http://www.scielo.br/pdf/ci/v35n2/a02v35n2.pdf >. Acesso em: 08 nov. 2018.

FOUCAULT, M. Prefácio. In: FOUCAULT, M. As palavras e as coisas: uma arqueologia das ciências humanas. São Paulo: Martins Fontes, 1999, p. ix-xxii.

FOUCAULT, M. O corpo utópico, as heterotopias. São Paulo: N-1, 2013a.

FOUCAULT, M. De espaços outros. Estudos Avançados, v. 27, n. 79, p. 113-122, 2013 b. Disponível em: <http://dx.doi.org/10.1590/S0103-4014201300030000>. Acesso em: 25 out. 2018.

FLUSSER, V. Uma biblioteca verdadeiramente pública. Revista da Escola de Biblioteconomia da UFMG, Belo Horizonte, v. 9, n. 2, p. 131-138, set. 1980. Disponível em: <http://portaldeperiodicos.eci.ufmg.br/reb/>. Acesso em: 15 dez. 2017.

FUNDAÇÃO BIBLIOTECA NANCIONAL. Biblioteca pública: princípios e diretrizes. 2. ed. rev. ampl. Rio de Janeiro: FBN, 2010. (Documentos Técnicos, 6).

GOMES, S. C. Bibliotecas e sociedade na primeira república brasileira: fatores sócioculturais que atuaram na criação e instalação de bibliotecas de 1980 a 1930. 1981. Dissertação (Mestrado em Administração de Bibliotecas) - Escola de Biblioteconomia, UFMG, Belo Horizonte, 1981. 
JACOB, C. Ler para escrever: navegações alexandrinas. In: BARATIN, M.; JACOB, C. O poder das bibliotecas: a memória dos livros no ocidente. Tradução de Marcela Mortara. 3. ed. Rio de Janeiro: Ed. UFRJ, 2008. p. 45-73.

JOHNSON, P. Bibliography under topic headings: texts related to Foucault's concept of heterotopia. mar. 2018. Disponível em: 〈http://www.heterotopiastudies.com/bibliography $>$. Acesso em: 08 nov. 2018.

KNIGHT, K. Introduction: resolving the paradox of Foucault's Heterotopia. In: KNIGHT, K. Real places and impossible spaces: Foucault's heterotopia in the fiction of James Joyce, Vladimir Nabokov and W. G. Sebald. PhD thesis: University of East Anglia, 2014, p. 7-53.

LEMOS, A. A. B. Bibliotecas. In: CAMPELLO, B. S.; CALDEIRA, P. T. (Org.). Introdução às fontes de informação. 2. ed. Belo Horizonte: Autêntica, 2008.

MACHADO, E. C.; ELIAS JUNIOR, A. C.; ACHILLES, D. A biblioteca pública no espaço público: estratégias de mobilização cultural e atuação sócio-política do bibliotecário.

Perspectivas em Ciência da informação, Belo Horizonte, v. 19, n. esp., p. 115-117, dez. 2014. Disponível em: 〈http://dx.doi.org/10.1590/1981-5344/2263〉. Acesso em: 25 out. 2018.

MARTINS, W. A palavra escrita: história do livro, da imprensa e da biblioteca. 2. ed. rev. atual. São Paulo: Ática, 1996.

MEDEIROS, A. L. Biblioteca e cidadania. Sinais sociais, Rio de Janeiro, ano 4, p. 11-46, maio 2010. Disponível em:

<http://www.sesc.com.br/portal/publicacoes/sesc/revistas/sinaissociais/n13/n13 > . Acesso em: 04 maio 2018.

MILANESI, L. Ordenar para desordenar. São Paulo: Brasiliense, 1986.

MIRANDA, A. A missão da biblioteca pública no Brasil. Revista de Biblioteconomia de Brasília, Brasília, v. 6, n. 1, p. 69-75, jan./jun. 1978. Disponível em:

<https://tonarede.org.br/wp-content/uploads/2017/09/A-missao-da-bibliotecapu\%CC\%81blica-no-Brasil.pdf. Acesso em: 21 nov. 2017.

MOURA, M. A. Heterotopias, mundo comum e as bibliotecas públicas. Perspectivas em Ciência da informação, Belo Horizonte, v. 19, n. esp., p. 64-78, dez. 2014. Disponível em: $<$ http://www.scielo.br/scielo.php?script=sci arttext\&pid=S141399362014000500007\&lng=en\&nrm=iso>. Acesso em: 08 nov. 2018.

NOGUEIRA, M. C. D. A realidade da biblioteca pública. Revista da Escola de Biblioteconomia da UFMG, Belo Horizonte, v. 12, n. 2, p. 205-212, set. 1983. Disponível em: 〈http://portaldeperiodicos.eci.ufmg.br/reb/>. Acesso em: 15 dez. 2017.

RABELLO, O. C. P. Da biblioteca pública à biblioteca popular: análise das contradições de uma trajetória. Revista da Escola de Biblioteconomia da UFMG, Belo Horizonte, v. 16, n. 1, p. 19-42, mar. 1987. Disponível em: 〈http://portaldeperiodicos.eci.ufmg.br/reb/>. Acesso em: 15 dez. 2017. 
RADFORD, G. P.; RADFORD, M. L.; LINGEL, J. The library as heterotopia: Michel Foucault and the experience of library space. Journal of Documentation, v. 71, n. 4, p. 733$737,2015$.

RICOEUR, P. Aula n. 16: Mannheim. In: RICOEUR, P. A ideologia e a utopia. Belo Horizonte: Autêntica, 2015, p. 315-331.

SUAIDEN, E. J. Biblioteca pública brasileira: desempenho e perspectivas. 1979. 103 p. Dissertação (Mestrado em Biblioteconomia) - Universidade Federal da Paraíba, João Pessoa, 1979.

SUAIDEN, E. J. Biblioteca pública e informação à comunidade. São Paulo: Global, 1995.

SUAIDEN, E. J. A biblioteca pública no contexto da sociedade da informação. Ciência da Informação, Brasília, v. 29, n. 2, p. 52-60, 2000. Disponível em:

<http://www.scielo.br/pdf/ci/v29n2/a07v29n2.pdf >. Acesso em: 25 out. 2018.

UNESCO. Manifesto da IFLA/Unesco sobre bibliotecas públicas. 1994. Disponível em: $<$ https://www.ifla.org/files/assets/public-libraries/publications/PL-manifesto/pl-manifestopt.pdf>. Acesso em: 18 nov. 2017.

VERRI, G. M.; NEVES, F. I. As bibliotecas públicas em questão. Revista de

Biblioteconomia de Brasília, Brasília, v. 5, n. 1, jan./jun. 1977. 